\title{
MODELAGEM DE TRANSFERÊNCIA DE CALOR EM LEITO FIXO COLOCADO EM TAMBOR HORIZONTAL PARCIALMENTE PREENCHIDO E COM ROTAÇÃO INTERMITENTE
}

\author{
E. F. R. TADA ${ }^{1}$, A. BÜCK ${ }^{2}$, F. P. CASCIATORI ${ }^{1}$, J. C. THOMÉO ${ }^{1}$ \\ ${ }^{1}$ Universidade Estadual Paulista; Instituto de Biociências, Letras e Ciências Exatas; \\ Departamento de Engenharia e Tecnologia de Alimentos \\ ${ }^{2}$ Otto-von-Guericke University Magdeburg, Chair of Thermal Process Engineering \\ *e-mail: erikartada@gmail.com
}

\begin{abstract}
RESUMO
O objetivo deste trabalho foi modelar a transferência de calor em um leito fixo colocado em tambor rotativo parcialmente preenchido e com rotação intermitente, visando sua utilização futura como biorreator para fermentação em estado sólido. Para tanto, foi feito um estudo de caso utilizando um leito de partículas inertes composto de esferas de vidro acondicionado em um biorreator cilíndrico horizontal parcialmente preenchido, com temperatura interna de $45^{\circ} \mathrm{C}$ mantida através da camisa e de aeração forçada sobre o leito. Foi proposto um modelo bidimensional a uma fase, com variações de temperatura com as coordenadas angular e radial, com o tempo. Foram admitidas condições de contorno de primeira espécie para o raio máximo e de terceira espécie para a superfície do leito. Os resultados indicam simetria na distribuição de temperatura angular e radial e pouca influência da convecção devido ao baixo valor do coeficiente convectivo. O aumento de $h$ evidencia a convecção, mas a vazão de ar necessária para tal não é usual em ensaios fermentativos. Em 10 horas de simulação, a temperatura média correspondeu a $32,9^{\circ} \mathrm{C}$ sem rotação e a $36,4^{\circ} \mathrm{C}$ com rotação intermitente a cada 2 horas.
\end{abstract}

\section{INTRODUÇÃO}

Fermentação em estado sólido (FES) pode ser definida como um processo fermentativo em substrato sólido úmido atuante como fonte de nutrientes e/ou suporte inerte a microrganismos. A água se apresenta em quantidades suficientes apenas para $\mathrm{o}$ desenvolvimento microbiano, de forma complexa ou absorvida pela matriz sólida porosa (HESSELTINE, 1972; PANDEY, 1992). É uma técnica antiga no Oriente e atualmente tem se mostrado uma interessante alternativa para obtenção de compostos de alto valor agregado, tais como ácidos orgânicos, aromas, antibióticos, agentes biorreguladores, enzimas industriais e bioetanol (BHARGAV et al., 2008).

A literatura discute diversas vantagens quanto à utilização de FES diante de outros processos fermentativos como, por exemplo, maiores rendimentos na produção de compostos de interesse e fácil adaptação do microrganismo às condições do processo, especialmente fungos filamentosos (HESSELTINE, 1987). Este último está 
relacionado principalmente ao uso de resíduos agroindustriais úmidos, que simulam as condições naturais de crescimento do microrganismo. Além disso, essa prática apresenta-se como uma opção para o destino de materiais com aplicações restritas (HÖLKER; LENZ, 2005).

Apesar de uma série de vantagens, a FES ainda é um processo executado apenas em biorreatores em escala de frascos ou de bancada. Devido à complexidade das interações entre substrato, microrganismo e metabólitos, a operação de biorreatores e o controle de variáveis de interesse tornam-se um desafio na ampliação de escala. Dentre as principais variáveis a serem controladas, a temperatura destaca-se por estar diretamente relacionada ao metabolismo microbiano e à produção de compostos de interesse (DALSENTER et al., 2005).

Dentre as arquiteturas de biorreatores disponíveis para a FES, os de tambor rotativo são interessantes por possibilitar várias alterativas de controle de temperatura e umidade do substrato. Neste biorreator, um cilindro horizontal é parcialmente preenchido com o substrato inoculado. Os maiores períodos de fermentação ocorrem com o meio de cultivo estático, mas periodicamente o tambor é feito girar para uniformizar a temperatura e a umidade do meio, podendo água ser aspergida sobre a superfície das partículas para arrefecer a elevação de temperatura e repor a água perdida do meio poroso para o ar ao longo da fermentação.

$\mathrm{Na}$ ampliação de escala, a modelagem matemática é uma interessante ferramenta que fornece informações sobre o desempenho do processo e auxilia na compreensão dos fenômenos envolvidos (MITCHELL; VON MEIEN; KRIEGER, 2003). A literatura fornece diversas pesquisas acerca da modelagem matemática aplicada à fermentação em estado sólido na última década, o que indica o interesse dos pesquisadores na ampliação de escala desta tecnologia (VAN DE LAGEMAAT; PYLE, 2005; FANAEI; VAZIRI, 2009; BÜCK et al., 2015).

Para fornecer dados próximos à realidade, o modelo matemático deve envolver todos os mecanismos existentes no processo. $\mathrm{Na}$ transferência de calor em biorreatores são predominantes os mecanismos convectivos e condutivos, além da contribuição da mistura e movimentação das partículas do leito.

Nesse sentido, este trabalho propõe-se a compreender e modelar os mecanismos de transferência de calor em leitos inertes, aplicados a biorreator do tipo tambor rotativo durante a fase estacionária e com rotação intermitente com vistas à sua futura aplicação para fermentação em estado sólido.

\section{MATERIAIS E MÉTODOS}

\subsection{Biorreator}

Este estudo de caso baseou-se nas condições operacionais de um biorreator do tipo tambor rotativo, construído em aço inoxidável com $30 \mathrm{~cm}$ de diâmetro interno e $74 \mathrm{~cm}$ de comprimento com configuração similar aos dos grupos de pesquisa da Universidade de Wagningen, Holanda, e da Universidade de São Paulo (OOSTRA; TRAMPER; RINZEMA, 2000; EDUARDO, 2010).

Devido à sua configuração, este equipamento admite operação com grau de enchimento volumétrico de até $60 \%$, determinado através de uma relação entre a área transversal ocupada pelas partículas e a área transversal total. Neste estudo, foi utilizado grau de enchimento de 0,3.

Este biorreator é dotado de recursos de rotação com defletores longitudinais e manutenção da temperatura através de camisa externa, aeração forçada e eventual aspersão de água. 
A aeração forçada se dá pela introdução de ar sobre o leito de partículas, estabelecendo-se o mecanismo de transferência de calor por convecção na superfície. $\mathrm{O}$ ar de entrada é mantido em temperatura de $45^{\circ} \mathrm{C}$ e vazão de $5 \mathrm{~L} / \mathrm{min}$. Esta vazão foi definida por Zanelato et al (2012) para operação em biorreator de leito fixo, e posteriormente utilizada por Grajales (2014) para estudos de fermentação em estado sólido neste biorreator rotativo.

A camisa externa é mantida também a $45^{\circ} \mathrm{C}$ por meio de um banho termostático. A temperatura de $45^{\circ} \mathrm{C}$ a que é mantido o processo é desejada por ser a temperatura ótima de crescimento do fungo termofílico Myceliophtora thermophila I-1D3b, utilizado por Grajales (2014) em ensaios para produção de enzimas celulolíticas.

\subsection{Parâmetros do modelo}

Para a compreensão dos fenômenos de transferência de calor no interior do biorreator, foi adotado um leito inerte composto por esferas de vidro de $0,3 \mathrm{~cm}$ de diâmetro. Uma estimativa da porosidade do leito, $\varepsilon$, foi calculada a partir de uma relação apresentada por Casciatori et al. (2014), correspondente a 0,35 . Outras propriedades do leito, tais como densidade $\left(\rho_{b}\right)$, calor específico $\left(C p_{b}\right)$ e condutividade térmica efetiva $\left(k_{b}\right)$ foram estimadas através das seguintes relações:

$\rho_{b}=(1-\varepsilon) \rho_{v}$

$C p_{b}=\left[(1-\varepsilon) C p_{v}\right]+\left(\varepsilon C p_{a}\right)$

$k_{b}=\left[(1-\varepsilon) k_{v}\right]+\left(\varepsilon k_{a}\right)$

As propriedades físicas e térmicas envolvidas foram consideradas constantes, exceto o coeficiente convectivo que é uma função do grau de enchimento.
O coeficiente convectivo de transferência de calor entre a superfície do leito e o ar foi estimado a partir da Equação 4, empregada para o escoamento paralelo de fluidos newtonianos a placas planas em escoamento laminar.

$h=\frac{0,664 \operatorname{Re}^{\frac{1}{2}} \operatorname{Pr}^{\frac{1}{3}} k_{a}}{L}$

onde $R e$ é o adimensional de Reynolds, $\operatorname{Pr}$ é o adimensional de Prandt e $L$ é o comprimento da placa plana. Durante a simulação foi considerado um coeficiente convectivo médio, pois foram desprezadas quaisquer variações do longo do comprimento.

$\mathrm{Na}$ Tabela 1 estão apresentadas as estimativas dos parâmetros requisitados neste modelo.

Tabela 1 - Valores dos parâmetros empregados na modelagem, assumidos constantes.

\begin{tabular}{ccc}
\hline Parâmetro & Valor & Referência \\
\hline$C p_{a}$ & $1005 \mathrm{~J} / \mathrm{kg}^{\circ} \mathrm{C}$ & \\
$C p_{v}$ & $840 \mathrm{~J} / \mathrm{kg}^{\circ} \mathrm{C}$ & \\
$k_{a}$ & 0,02745 & \\
$k_{v}$ & $0,78 \mathrm{~W} / \mathrm{m}^{\circ} \mathrm{C}$ & INCROPERA, \\
$\rho_{a}$ & $1,1099 \mathrm{~kg} / \mathrm{m}^{3}$ & 2008 \\
$\rho_{v}$ & $2700 \mathrm{~kg} / \mathrm{m}^{3}$ & \\
$\mu_{a}$ & $1,93.10^{-5} \mathrm{~Pa} . \mathrm{s}$ & \\
$T_{a}$ & $45^{\circ} \mathrm{C}$ & GRAJALES, \\
$T_{p}$ & $45^{\circ} \mathrm{C}$ & 2014 \\
\hline
\end{tabular}

\subsection{Modelo Matemático}

O modelo foi proposto a partir de adaptações em modelos pseudo-homogêneos disponíveis na literatura clássica para a transferência de calor em leitos fixos (SAUCEDO-CASTAÑEDA et al., 1990; SANGSURASAK; MITCHELL, 1998). O fenômeno foi descrito por meio de uma equação diferencial bidimensional a uma fase 
para a situação de um cilindro horizontal parcialmente preenchido. Variações axiais foram negligenciadas, uma vez que se esperam perdas de calor consideráveis nas extremidades axiais do biorreator, pois as mesmas não são isoladas termicamente do ambiente. O modelo é dado pela Equação 5, onde cada termo possui a unidade $\mathrm{W} / \mathrm{m}^{3}$.

$$
\rho_{b} C p_{b} \frac{\partial T}{\partial t}=\frac{k_{b}}{r}\left(\frac{\partial T}{\partial r}\right)+k_{b}\left(\frac{\partial^{2} T}{\partial r^{2}}\right)+\frac{k_{b}}{r^{2}}\left(\frac{\partial^{2} T}{\partial \theta^{2}}\right)
$$

O centro geométrico da circunferência foi adotado como ponto de referência para as considerações espaciais das variáveis ângulo e raio. O leito foi considerado horizontalmente simétrico e cada incremento no ângulo possui um valor de raio do leito, como mostrado na Figura 1.

Figura 1 - Diagrama esquemático da vista frontal do biorreator com a localização espacial para as variações angular e radial.



O modelo fornece a evolução temporal de temperatura no interior de um leito cilíndrico horizontal durante os momentos em que permaneceu estático, considerando variações radiais e angulares de temperatura e está habilitado para simulação com diferentes graus de enchimento.

\subsubsection{Condições de contorno}

Foram consideradas uma condição inicial e quatro condições de contorno, como mostrado nas Equações (6) a (10).

$$
\begin{array}{ll}
t=0 & T=T_{0} \\
\theta=\theta_{i}, & \frac{\partial T}{\partial \theta}=-\frac{h}{k_{b}}\left(T_{a}-T\right) \\
\theta=\theta_{f}, & \frac{\partial T}{\partial \theta}=-\frac{h}{k_{b}}\left(T_{a}-T\right) \\
r=0, & \frac{\partial T}{\partial r}=-\frac{h}{k_{b}}\left(T_{a}-T\right) \\
r=R, & T=T_{p}
\end{array}
$$

As Equações (7) a (9) referem-se à transferência de calor por convecção na superfície do leito provocada pela aeração forçada. A condição de contorno apresentada pela Equação (10) assume que as partículas em contato com a parede do biorreator são mantidas à mesma temperatura da parede, de modo que não foram consideradas resistências da parede do biorreator à transferência de calor.

\subsubsection{Solução numérica}

As equações diferenciais parciais foram discretizadas através de aproximações das derivadas parciais por metodologia de diferenças finitas, e escritas em linguagem Matlab $^{\circledR}$ R2012b versão 7.0 (MathWorks Inc., Natick, USA) na forma de equações diferenciais ordinárias para cada variável. As equações diferenciais ordinárias resultantes foram solucionadas simultaneamente pelo método das fórmulas de diferenciação numérica com o passo da variável tempo definido pelo solucionador ode15s. 
A temperatura média foi determinada através de um balanço de entalpia, como mostrado na Equação (11).

$$
T_{m}=\frac{L \rho_{b} C p_{b}}{m_{b} C p_{b, m}} \int_{o}^{\theta} \int_{r_{1}}^{r_{2}} T_{b}(r, \theta) \cdot r \cdot d r \cdot d \theta
$$

onde $m_{b}$ é a massa do leito e $C p_{b, m}$ é o calor específico médio do leito.

\section{RESULTADOS E DISCUSSÕES}

A superfície de resposta gerada pela simulação apresenta simetria na evolução da temperatura angular e radial. Na Figura 2 estão apresentados os dados para a primeira hora de simulação com grau de enchimento de 0,3 .

Figura 2 - Perfil de temperatura em função das variações angulares e radiais em leito de esferas de vidro em biorreator do tipo tambor rotativo (Grau de enchimento $=0,3 ; \mathrm{t}=1 \mathrm{~h} ; h$ $\left.=0,17 \mathrm{~W} / \mathrm{m}^{2 \circ} \mathrm{C} ; \mathrm{T}_{\mathrm{o}}=25^{\circ} \mathrm{C}\right)$.

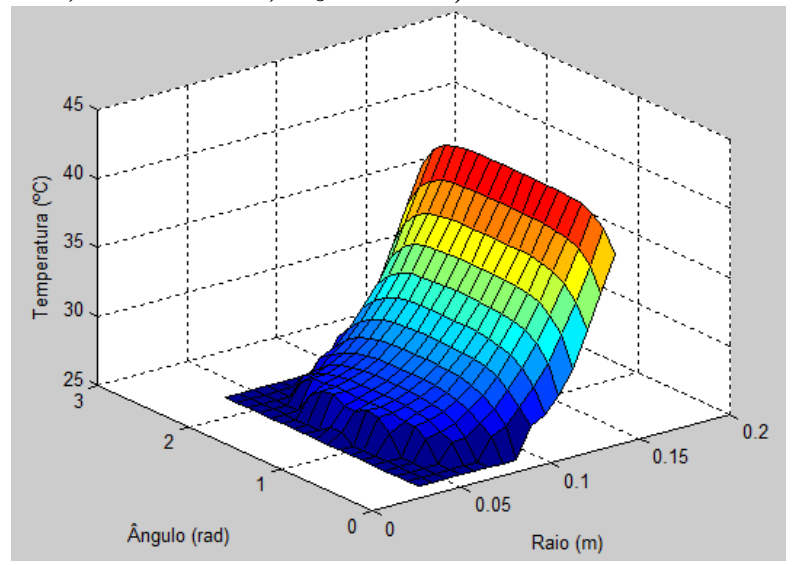

Para a primeira hora de simulação, a região fria concentrou-se na superfície do leito, com temperatura de $25,5^{\circ} \mathrm{C}$ no centro angular. As maiores temperaturas foram registradas nas regiões do leito próximas à parede do biorreator. Isso porque, uma vez que foram desconsideradas resistências à transferência de calor na parede, a condição de contorno de primeira espécie empregada nesta região obriga o aumento imediato de temperatura. Este aumento de temperatura foi verificado logo no primeiro segundo de simulação, em que o leito em contato com a parede registrou um incremento de $0,1^{\circ} \mathrm{C}$ na temperatura inicial. Para as extremidades angulares do leito, na interface leito-paredear, em que se considerou condição de contorno de terceira espécie, não houve aumento de temperatura neste intervalo de tempo.

A literatura sugere que os mecanismos convectivos são mais expressivos na transferência de calor em comparação com a condução principalmente em experimentos com leito úmido, provocando resfriamento evaporativo (GRAJEK, 1988; SAUCEDOCASTANEDA et al., 1990; SANGSURASAK; MITCHELL, 1995). Entretanto, no caso aqui estudado, verifica-se que o coeficiente convectivo entre o ar e o leito $(h)$ assume um valor baixo $(h=0,17$ $\mathrm{W} / \mathrm{m}^{2 \circ} \mathrm{C}$ ), próximo a valores usualmente encontrados para convecção natural. Isso se dá pelo fato da estimativa do coeficiente convectivo ser uma função da vazão de ar adotada e da área livre de escoamento do fluido. Desse modo, o emprego de menores graus de enchimento promove uma maior área livre para escoamento no sobre-espaço acima das partículas e, consequentemente, menor valor para coeficiente convectivo.

Admitindo-se $h$ igual a $1,7 \mathrm{~W} / \mathrm{m}^{2}{ }^{\circ} \mathrm{C}$, dez vezes maior que $\mathrm{o}$ original calculado, verificam-se mudanças no perfil de temperatura $\log o$ na primeira hora de simulação, provocadas pela influência do mecanismo convectivo, como mostrado na Figura 3.

Figura 3 - Perfil de temperatura em função das variações angulares e radiais em leito de esferas de vidro em biorreator do tipo tambor 
rotativo (Grau de enchimento $=0,3 ; \mathrm{t}=1 \mathrm{~h} ; h$ $\left.=1,7 \mathrm{~W} / \mathrm{m}^{2 \circ} \mathrm{C} ; \mathrm{T}_{\mathrm{o}}=25^{\circ} \mathrm{C}\right)$.

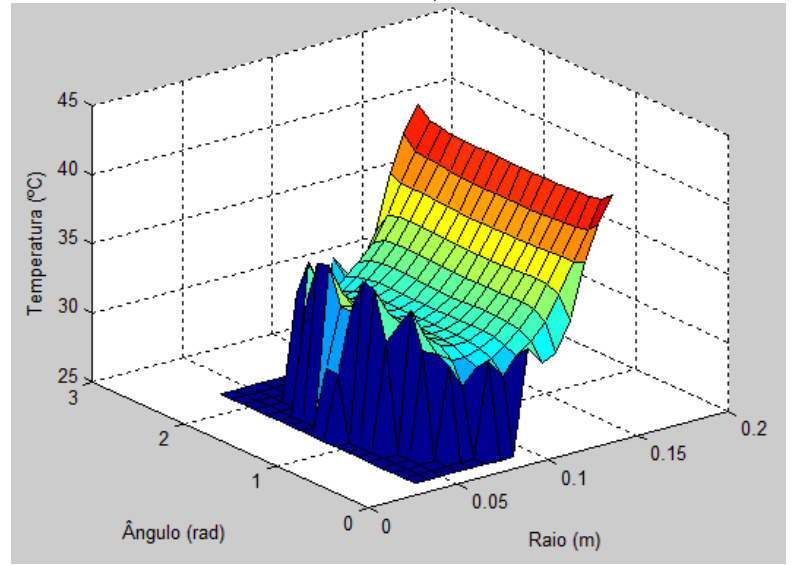

As posições radiais iniciais do leito, no instante $3600 \mathrm{~s}$ (1 hora), registraram temperatura de $29,5^{\circ} \mathrm{C}$ para o centro angular, o que indica transferência de calor provocada pelo aumento no valor de $h$. Neste caso, o aumento do valor de $h$ seria provocado unicamente pelo aumento no fornecimento de ar ao sistema. Assim, para alcançar $h=1,7$ $\mathrm{W} / \mathrm{m}^{2 \circ} \mathrm{C}$, o processo deveria ser alimentado por uma vazão de ar de $200 \mathrm{~L} / \mathrm{min}, 40$ vezes maior que a utilizada por Zanelato et al. (2012) e Grajales (2014) em processos de FES.

Na literatura de FES, Rahardjo et al. (2005) cultivaram Aspergillus oryzae em farinha de trigo em biorreator de bandeja (leito fixo) com aeração de $0,4 \mathrm{~L} / \mathrm{min}$. Melikoglu, Lin e Webb (2015) obtiveram resultados interessantes na produção de enzimas em resíduos de pão por Aspergillus awamori, com vazão de ar de $1,5 \mathrm{~L} / \mathrm{min}$ em leito fixo. Dessa forma, apesar de se mostrarem interessantes quanto à transferência de calor através da superfície do leito de partículas, maiores valores para o coeficiente convectivo demandariam vazões de ar muito acima das usualmente empregadas em FES.

$\mathrm{O}$ aumento da temperatura de entrada do ar para $60^{\circ} \mathrm{C}$ provoca o aumento em $1^{\circ} \mathrm{C}$ na temperatura da superfície do leito no centro angular após 3600 s (1 hora) de simulação.
Isso poderia ser considerado interessante pois, apesar do baixo valor de $h$, as partículas recebem a troca por convecção com maior intensidade. Entretanto, após 2 horas de simulação as extremidades angulares do leito registraram temperaturas superiores a $45^{\circ} \mathrm{C}$, atingindo $50^{\circ} \mathrm{C}$ em aproximadamente 3,5 horas. Isto não é desejado neste processo, pois as reações bioquímicas estão diretamente relacionadas à temperatura. Assim, o uso de temperaturas operacionais acima da ótima de crescimento não é usual em ensaios fermentativos.

A evolução da temperatura em função das posições angulares e radiais mantém o perfil similar com o passar do tempo. A Figura 4 apresenta a superfície de resposta gerada no instante 36000 segundos (10 horas) de simulação.

A temperatura máxima do leito em 10 horas de simulação com $h$ de $0,17 \mathrm{~W} / \mathrm{m}^{2{ }^{\circ}} \mathrm{C}$ foi alcançada nas extremidades angulares em contato com a parede e correspondeu a $44,2^{\circ} \mathrm{C}$. Nesta posição, este ponto do leito está exposto a duas condições de contorno radiais: convecção pela superfície e temperatura constante e igual à da parede do tambor. Entretanto, é provável que, mesmo que exposto à convecção, a condução seja predominante, pelo fato de encontrar-se em contato com a parede. Assim, a condição de contorno dominante é a de primeira espécie, uma vez que este ponto do leito se encontra dentro da camada limite térmica da parede.

Um dado quantitativo que representa a superioridade da condução frente à convecção é a taxa total de calor trocado por ambos os mecanismos. Tomando $h=0,17 \mathrm{~W} / \mathrm{m}^{\circ} \mathrm{C}$ e a área da superfície do leito, tem-se taxa de transferência de calor por convecção igual a 0,75 W. Supondo condução no sentido radial no centro angular do leito, a taxa corresponde a 2,33 W, que é quase três vezes maior que a taxa de transferência de calor por convecção. 
Figura 4 - Perfil de temperatura em função das variações angulares e radiais em leito de esferas de vidro em biorreator do tipo tambor rotativo (Grau de enchimento $=0,3 ; \mathrm{t}=10 \mathrm{~h}$; $\left.h=0,17 \mathrm{~W} / \mathrm{m}^{2 \circ} \mathrm{C} ; \mathrm{T}_{\mathrm{o}}=25^{\circ} \mathrm{C}\right)$.

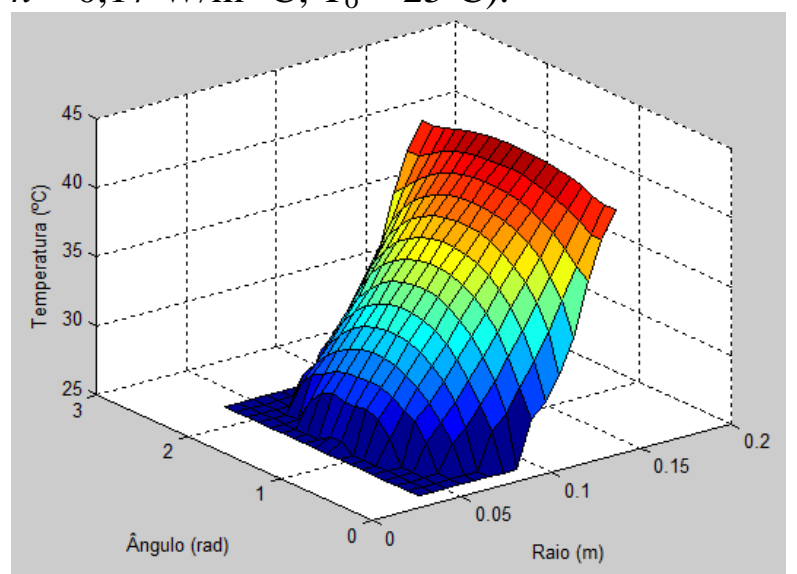

Nota-se que o centro radial do leito assume temperaturas mais elevadas em comparação com o instante $3600 \mathrm{~s}$ (1 hora de simulação). Entretanto, a face superficial do leito mantém temperatura praticamente constante e igual à inicial, o que sugere que a mudança na temperatura do interior do leito seja provocada predominantemente pela influência da condução de calor interpartículas.

As interações entre as partículas podem ser observadas a partir de modelos a duas fases desde que contemplados todos os fenômenos envolvidos. No entanto, este tipo de modelo é complexo e requer diversas considerações e aproximações como, por exemplo, o posicionamento das partículas e a movimentação do fluido no interior do leito. Neste estudo de caso, as interações interpartículas não são apresentadas pelo modelo, evidenciando suas deficiências e fazendo com que estas sejam apenas supostas através das respostas obtidas na simulação.

Partindo-se da temperatura inicial de $25^{\circ} \mathrm{C}$ e estabelecendo-se rotação intermitente a cada duas horas para homogeneização do leito, o perfil de temperatura em função das variações radiais e angulares permaneceu similar à situação totalmente estática. A diferença concentrou-se no fato de que, a cada rotação, a temperatura inicial assumiu o valor médio da temperatura em todo o leito.

A rotação possibilitou o alcance da temperatura média de $36,4^{\circ} \mathrm{C}$ no leito ao final de 10 horas de simulação. As Figuras 5 a 7 apresentam os perfis de temperatura após 2, 6 e 10 horas de simulação.

Figura 5 - Perfil de temperatura em função das variações radiais e angulares após 2 horas de simulação (Grau de enchimento $=0,3 ; \mathrm{t}=$ $\left.2 \mathrm{~h} ; h=0,17 \mathrm{~W} / \mathrm{m}^{2}{ }^{\circ} \mathrm{C} ; \mathrm{T}_{\mathrm{o}}=25^{\circ} \mathrm{C}\right)$.

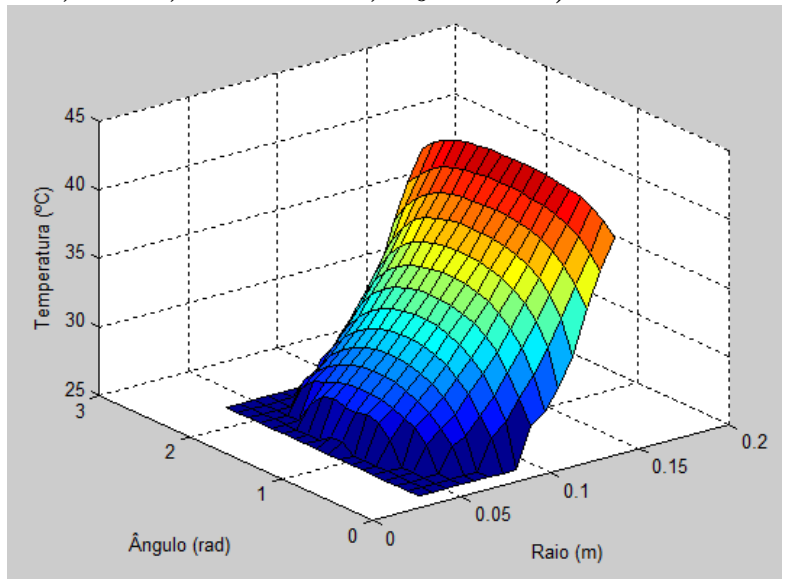

Figura 6 - Perfil de temperatura em função das variações radiais e angulares após 6 horas de simulação com rotação a cada 2 horas (Grau de enchimento $=0,3 ; \mathrm{t}=6 \mathrm{~h} ; h=0,17$ $\left.\mathrm{W} / \mathrm{m}^{2 \circ} \mathrm{C} ; \mathrm{T}_{\mathrm{o}}=34,5^{\circ} \mathrm{C}\right)$.

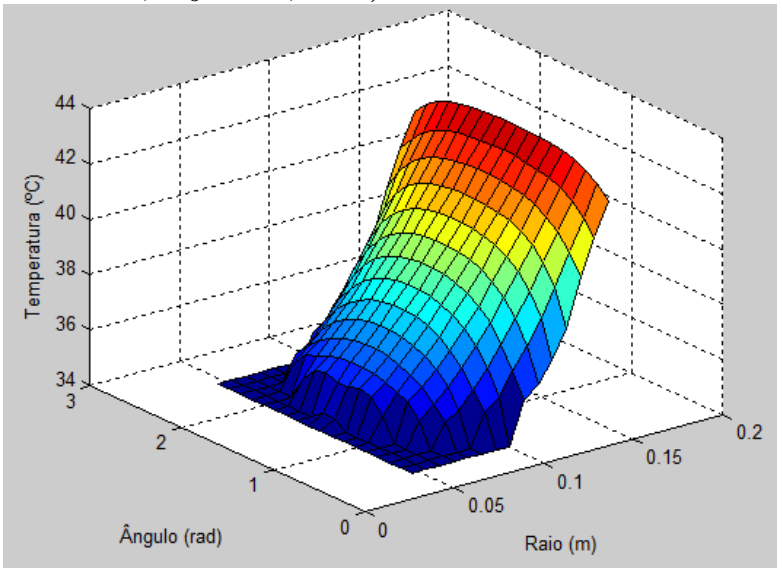

Figura 7 - Perfil de temperatura em função das variações radiais e angulares após 10 horas de simulação com rotação a cada 2 
horas (Grau de enchimento $=0,3 ; \mathrm{t}=10 \mathrm{~h} ; h$ $\left.=0,17 \mathrm{~W} / \mathrm{m}^{2 \circ} \mathrm{C} ; \mathrm{T}_{\mathrm{o}}=36,2^{\circ} \mathrm{C}\right)$.

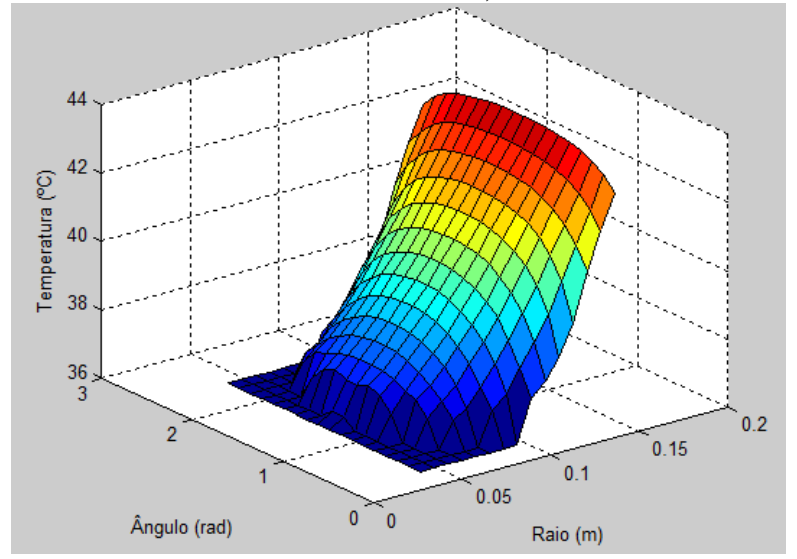

Nota-se que após 6 horas de simulação houve aumento da temperatura média do leito em $10,7^{\circ} \mathrm{C}$ em relação à temperatura inicial de $25^{\circ} \mathrm{C}$. As demais 4 horas de simulação apresentaram aumento de apenas $0,7^{\circ} \mathrm{C}$.

A comparação entre as simulações estática e com intermitência na rotação podem ser realizadas comparando-se as temperaturas médias do leito após determinados intervalos de tempo. Na Tabela 2 estão apresentadas as temperaturas médias para cada situação a cada 2 horas de simulação.

Tabela 2 - Temperaturas médias registradas no leito de partículas em $0,2,4,6,8$ e 10 horas de simulação em situação de leito estático e com rotação intermitente (Grau de enchimento $\left.=0,3 ; h=0,17 \mathrm{~W} / \mathrm{m}^{2 \circ} \mathrm{C}\right)$.

\begin{tabular}{|c|c|c|}
\hline \multirow[b]{2}{*}{ Tempo (h) } & \multicolumn{2}{|c|}{ Temperatura $\left({ }^{\circ} \mathrm{C}\right)$} \\
\hline & Leito estático & $\begin{array}{c}\text { Rotação } \\
\text { intermitente }\end{array}$ \\
\hline 0 & 25 & 25 \\
\hline 2 & 31,7 & 31,7 \\
\hline 4 & 32,7 & 34,5 \\
\hline 6 & 32,9 & 35,7 \\
\hline 8 & 32,9 & 36,2 \\
\hline 10 & 32,9 & 36,4 \\
\hline
\end{tabular}

Os dados da Tabela 2 propõem que o regime de rotação estabelecido contribui para a homogeneização da temperatura das partículas, pois a temperatura média do leito com rotação intermitente se aproxima mais dos $45^{\circ} \mathrm{C}$ desejados ao final de 10 horas de simulação; enquanto que a temperatura média do leito permanentemente estático neste mesmo instante é próxima àquela no instante 10800 s (3 horas) de simulação para o leito com rotação intermitente. Assim, a simulação com rotação intermitente sugere que a mistura e a movimentação das partículas do leito colaboram para a sua homogeneização, uma vez que possibilitam que partículas localizadas em regiões mais frias entrem em contato e efetuem troca térmica com partículas mais quentes.

O emprego de partículas regulares, homogêneas e inertes auxilia na compreensão dos fenômenos de transferência de calor, desde os mais básicos até os mais complexos. Para a compreensão dos fenômenos básicos de transferência de calor, neste trabalho, foi considerado um leito homogêneo de partículas inertes, ou seja, o leito foi observado como um corpo sólido único, resultando em um modelo a uma fase.

\section{CONCLUSÕES}

O modelo bidimensional a uma fase proposto para a transferência de calor na situação de um biorreator cilíndrico e horizontal parcialmente preenchido apresenta simetria na distribuição de temperatura em função de variações angulares e radiais.

O coeficiente convectivo $h$ entre o ar e a superfície do leito possui valor próximo à convecção natural, predominando a condição de contorno de primeira espécie entre a parede do biorreator e o leito. Maiores valores para $h$ evidenciariam a influência do mecanismo convectivo, mas não são usuais em ensaios fermentativos, bem como maiores temperaturas de entrada de ar.

A intermitência na rotação das partículas uniformiza a temperatura, aproximando o sistema da temperatura adotada como controle do processo em um 
menor tempo de simulação em comparação com a situação em que não há rotação.

A configuração do biorreator e a consideração do leito como homogêneo, regular e inerte possibilitaram a compreensão e a simulação dos fenômenos de transferência de calor a partir de um modelo bidimensonal a uma fase.

\section{NOMENCLATURA}

$\rho_{b}$ - Densidade do leito, $\mathrm{kg} / \mathrm{m}^{3}$

$\rho_{a}$ - Densidade do ar, $\mathrm{kg} / \mathrm{m}^{3}$

$\rho_{v}$ - Densidade do vidro, $\mathrm{kg} / \mathrm{m}^{3}$

$C p_{b}-$ Calor específico do leito, $\mathrm{J} / \mathrm{kg}^{\circ} \mathrm{C}$

$C p_{a}-$ Calor específico do ar, $\mathrm{J} / \mathrm{kg}^{\circ} \mathrm{C}$

$C p_{v}$ - Calor específico do vidro, $\mathrm{J} / \mathrm{kg}^{\circ} \mathrm{C}$

$C p_{b, m}$ - Calor específico médio do leito,

$\mathrm{J} / \mathrm{kg}^{\circ} \mathrm{C}$

$\varepsilon$ - Porosidade do leito

$k_{b}$ - Condutividade térmica efetiva do leito, $\mathrm{W} / \mathrm{m}^{\circ} \mathrm{C}$

$k_{a}$ - Condutividade térmica do ar, $\mathrm{W} / \mathrm{m}^{\circ} \mathrm{C}$

$k_{v}$ - Condutividade térmica do vidro, $\mathrm{W} / \mathrm{m}^{\circ} \mathrm{C}$

$\mu_{a}-$ Viscosidade dinâmica do ar, Pa.s

$m_{b}-$ Massa do leito, $\mathrm{kg}$

$T_{a}$ - Temperatura do ar de entrada, ${ }^{\circ} \mathrm{C}$

$T_{o}$ - Temperatura inicial do leito, ${ }^{\circ} \mathrm{C}$

$T_{p}$ - Temperatura da parede do biorreator, ${ }^{\circ} \mathrm{C}$

$T_{m}$ - Temperatura média do leito, ${ }^{\circ} \mathrm{C}$

$R e$ - Adimensional de Reynolds

$\mathrm{Pr}$ - Adimensional de Prandtl

$h$ - Coeficiente convectivo médio de transferência de calor entre ar e leito, $\mathrm{W} / \mathrm{m}^{2{ }^{\circ}} \mathrm{C}$

$r$ - Raio, $\mathrm{m}$

$\theta-$ Ângulo, $\mathrm{rad}$

$T$ - Temperatura, ${ }^{\circ} \mathrm{C}$

\section{REFERÊNCIAS}

BHARGAV, S., PANDA, B. P., ALI, S., JAVED, S. Solid-state Fermentation: An Overview. Chemical \& Biochemical Engineering Quartely, v.22(1), p.49-70, 2008.
BÜCK, A., CASCIATORI, F. P., THOMÉO, J. C., TSOTSAS, E. Model-based Control of Enzyme Yield in Solid-state Fermentation. Procedia Engineering, v.102, p.362-371, 2015.

CASCIATORI, F. P., LAURENTINO, C. L., TABOGA, S. R., CASCIATORI, P. A., THOMÉO, J. C. Structural properties of beds packed with agro-industrial solid by-products applicable for solid-state fermentation: Experimental data and effects on process performance. Chemical Engineering Journal, v.255, p.214-224, 2014.

DALSENTER, F. D. H., VICCINI, G., BARGA, M. C., MITECHELL, D. A., KRIEGER, N. A mathematical model describing the effect of temperature variation on the kinetics of microbial growth in solidstate culture. Process Biochemistry, v.40, p.801-807, 2005.

EDUARDO, M. P. Desempenho e Homogeneidade de Cultivos em Meio Sólido de Monascus sp. em Biorreator do Tipo Tambor com Agitação Interna: Efeito do Padrão de Agitação. 2010. 145 f. Tese (Doutorado em Engenharia) - Escola Politécnica da Universidade de São Paulo, São Paulo, 2010.

FANAEI, M. A., VAZIRI, B. M. Modeling of temperature gradients in packed-bed solidstate bioreactors. Chemical Engineering and Processing: Process Intensification, v.44, p.446-451, 2009.

GRAJALES, L. M. Desenvolvimento de um biorreator rotativo para produção de enzimas celulolíticas por fermentação em estado sólido. 2014. 157 f. Tese (Doutorado em Engenharia e Ciência de Alimentos) Instituto de Biociências, Letras e Ciências Exatas, Universidade Estadual Paulista, São José do Rio Preto, 2014. 
GRAJEK, W. Cooling Aspects of Solid-State Cultures of Mesophilic and Thermophilic Fungi. Journal of Fermentation Technology, v.66, p.675-679, 1988.

HESSELTINE, C. W. Solid State Fermentations. Illinois: Biotechnology and Bioengineering, 1972.

HESSELTINE, C. W. Solid state fermentation - An overview. Internation Biodeterioration, v.23, p.79-89, 1987.

HÖLKER, U., LENZ, J. Solid-state fermentation - are there any biotechnological advantages? Current Opinion in Microbiology, v.8, p.301-306, 2005.

INCROPERA, F. P. Fundamentos de Transferência de Calor e Massa. $6^{\mathrm{a}}$ ed. Rio de Janeiro: Editora LTC. p.599-600.

MELIKOGLU, M., LIN, C. S. K., WEBB, C. Solid state fermentation of waste bread pieces by Aspergillus awamori: Analysing the effects of airflow rate on enzyme production in packed bed bioreactors. Food and Bioproducts Processing, v.95, p.63-75, 2015.

MITCHELL, D. A., VON MEIEN, O. F., KRIEGER, N. Recent developments in modeling of solid-state fermentation: heat and mass transfer in bioreactors. Biochemical Engineering Journal, v.13, p.137-147, 2003.

OOSTRA, J., TRAMPER, J., RINZEMA, A. Model-based bioreactor selection for largescale solid-state cultivation of Coniothyrium minitans spores on oats. Enzyme and Microbial Technology, v.27, p.652-663, 2000.

PANDEY, A. Recent process developments in solid-state fermentation. Process Biochemistry, v.27, p.109-117, 1992.
RAHARDJO, Y. S. P. WEBER, F. J., HAEMERS, S., TRAMPER, J., RINZEMA, A. Aerial mycelia of Aspergillus oryzae accelerate alfa-amylase production in a model solid-state fermentation system. Enzyme and Microbial Technology, v.36, p.900-902, 2005.

SANGSURASAK, P., MITCHELL, D. A. The investigation of transient mutidimensional heat transfer in solid state fermentation. The Chemical Engineering Journal, v.60, p.199-204, 1995.

SAUCEDO-CASTAÑEDA, G., GUTIÉRREZ-ROJAS, M., BACQUET, G., RAIMBAULT, M., VINIEGRAGONZÁLEZ, G. Heat Transfer Simulation in Solid Substrate Fermentation. Biotechnology and Bioengineering, v.35, p.802-808, 1990.

VAN DE LAGEMAAT, J., PYLE, D. L. Modelling the uptake and growth kinetics of Penicillium glabrum in a tannic acidcontaining solid-state fermentation for tannase production. Process Biochemistry, v.40, p.1773-1782, 2005.

ZANELATO, A. I., SHIOTA, V. M., GOMES, E., SILVA, R. da, THOMÉO, J. C. Endoglucanase production with the newly isolated Myceliophtora sp. I-1D3b in a packed ned solid state fermentor. Brazilian Journal of Microbiology, v.43, p.1536-1544, 2012.

\section{AGRADECIMENTOS}

Os autores agradecem, pela concessão de bolsas e auxílio para desenvolvimento desta pesquisa, ao Conselho Nacional de Desenvolvimento Científico e Tecnológico CNPq (Proc. 131181/2014-9) e à Fundação de Amparo a Pesquisa do Estado de São Paulo FAPESP (Proc. 2014/23453-3) 